\title{
Visual Locomotion Scoring in the First Seventy Days in Milk: Impact on Pregnancy and Survival
}

\author{
R. C. Bicalho, ${ }^{* 1}$ F. Vokey, † H. N. Erb, ${ }^{*}$ and C. L. Guard ${ }^{*}$ \\ *Department of Population Medicine and Diagnostic Sciences, College of Veterinary Medicine, Cornell University, Ithaca, NY 14853 \\ †Cornell Cooperative Extension, PO Box 72, Lowville, NY 13367
}

\begin{abstract}
Our hypotheses were that cows classified as lame during the first $70 \mathrm{~d}$ in milk have more days from calving to conception and a greater hazard of dying or being culled compared with cows that were not classified as lame. Our objective was to estimate the detrimental effects of lameness on calving-to-conception interval and hazard of dying or being culled in lactating Holstein cows. Data were collected from 5 dairy farms located in upstate New York from November 2004 to June 2006. The design was a prospective observational cohort study. Cows were assigned a visual locomotion score (VLS) using a 5 -point scale: $1=$ normal, $2=$ presence of a slightly asymmetric gait, $3=$ the cow clearly favored 1 or more limbs (moderately lame), $4=$ severely lame, to $5=\mathrm{ex}$ tremely lame (nonweight-bearing lame). In total 1,799 cows were enrolled. In 2 alternative categorizations, cows were considered lame if at least 1 VLS was $\geq 3$ during the first $70 \mathrm{~d}$ in milk, and if at least 1 VLS was $\geq 4$ for the same period they were considered lame. Lameness (VLS $\geq 3$ ) was detected at least once in 26.5, $54.2,33.9,51.8$, and $39.3 \%$ of all cows in farms 1 to 5 , respectively. The hazard ratio of being detected pregnant was 0.85 for lame cows (VLS $\geq 3$ ) vs. nonlame cows; hence, lame cows were at a $15 \%$ lower risk of pregnancy than nonlame cows. When lameness was redefined as VLS $\geq 4$, the hazard ratio of been detected pregnant was 0.76 for lame cows vs. cows with VLS $<4$. Lameness increased the hazard ratio of culling/death, 1.45 and 1.74 for VLS $\geq 3$ and VLS $\geq 4$, respectively, vs. cows with VLS $<3$ and VLS $<4$, respectively. In summary, lameness significantly decreased the hazard of pregnancy and increased the hazard of culling/death. The detrimental effects were amplified when considering only severely lame and nonweight-bearing cows.
\end{abstract}

Key words: lameness, culling, reproduction, dairy cow

Received April 20, 2007.

Accepted June 20, 2007.

${ }^{1}$ Corresponding author: rcb28@cornell.edu

\section{INTRODUCTION}

Lameness is 1 of the 3 most important causes of economic losses in the North American dairy industry. Economic losses from lameness include decreased milk yield (Warnick et al., 2001; Green et al., 2002), impaired fertility (Hernandez et al., 2001; Melendez et al., 2003), and increased risk of culling (Esslemont and Kossaibati, 1997; Booth et al., 2004). Furthermore, the observation of lameness has been classified as the most representative animal-based indicator of welfare in dairy cattle (Whay et al., 2003). Lameness is perhaps the biggest challenge for dairies to overcome as society becomes more concerned with the origin of their food and the welfare of farm animals.

The detrimental effect of lameness on reproduction was reported by Sprecher et al. (1997) who described a lameness scoring system and its association with reproductive outcomes; cows considered lame before the end of the voluntary waiting period had impaired reproductive performance when compared with normal cows. Hernandez et al. (2005), using a modified version of the scoring system described by Sprecher et al. (1997), reported increased days from calving to conception for cows with high locomotion scores vs. cows with low locomotion scores. The prevalence of lameness early postpartum might affect reproduction by affecting feed intake, thus aggravating negative energy balance. Hammon et al. (2006) reported that negative energy status in the periparturient cow was associated with uterine health disorders. Garbarino et al. (2004) reported that cows classified as lame in the first 35 DIM had delayed resumption of postpartum cyclicity and that delayed ovarian cyclicity in lame cows would be reduced by $71 \%$ if lameness had been prevented.

Two reports associated lameness with increased risk of culling/death. Sprecher et al. (1997) reported that cows with lameness scores $>2$ were 8.4 times more likely to be culled. Booth et al. (2004) analyzed a large data set from New York State and reported that cows classified as lame were 2 times more likely to be culled than nonlame cows. The effect of lameness on hazard of culling might be due to decreased milk production and reproductive 
performance; however, severe lameness can require culling or euthanasia if mobility of the cow is severely affected.

Our hypotheses were that cows classified as lame during the first 70 DIM have more days from calving-toconception and higher hazard of culling/death compared with cows that were not classified as lame. Our objective was to estimate the detrimental effects of lameness on calving-to-conception interval and hazard of culling/ death in lactating Holstein cows.

\section{MATERIALS AND METHODS}

\section{Farms and Management}

The experiment was conducted on 5 commercial Holstein dairy farms located in New York State, from November 2004 to June 2006. Farms 1, 2, and 3 were located in Lewis County and consisted of 557, 350, and 1,000 milking cows, respectively. Farms 4 and 5 were located in Cayuga County and consisted of approximately 1,000 and 2,500 milking cows, respectively. Lactating dairy cows were housed in free-stall facilities and milked 3 times daily. Cows in the experiment were fed TMR diets formulated to meet or exceed the NRC (2001) nutrient requirements for lactating Holstein cows weighing $650 \mathrm{~kg}$ and producing $45 \mathrm{~kg}$ of $3.5 \%$ FCM.

\section{Study Design and Data Collection}

The design was a prospective observational cohort study; cohorts were based on either of 2 alternative dichotomizations of the visual locomotion scores (VLS); at least 1 VLS $\geq 3$, during the first $70 \mathrm{DIM}$ vs. always VLS $\leq 2$, and at least $1 \mathrm{VLS} \leq 4$ in the first 70 DIM vs. always $\mathrm{VLS} \leq 3$. Individual cow information was retrieved from DairyComp305 (Valley Agricultural Software, Tulare, $\mathrm{CA})$.

Visual locomotion scoring on farms 4 and 5 were done by 2 trained veterinarians, and for farms 1,2 , and 3 the VLS were performed by 2 technicians trained to perform VLS for the study. The system used was a 5-point scale ranging from 1 = normal, 2 = presence of a slightly asymmetric gait, $3=$ the cow clearly favored 1 or more limbs (moderately lame), $4=$ severely lame, to $5=$ extremely lame (nonweight-bearing lame). The observers recited the cow identification number and the VLS into a digital voice recorder while the cows were walking past the observers. Only cows < 70 DIM were scored for locomotion. The VLS was done every $14 \mathrm{~d}$, and each cow enrolled in the study received at least 2 scores and a maximum of 7 scores. The VLS were entered in a spreadsheet, and individual cow information used in the analysis was extracted from DairyComp305 into another spreadsheet, the table containing the VLS information was then merged with the table extracted from DairyComp305 using JMP 6.0.2 (SAS Institute, Cary, NC). Two queries were made using JMP to create the 2 new dichotomous variables for the VLS $\geq 3$ and VLS $\geq 4$. Therefore, there were 2 definitions for lameness; first, lameness was defined as the occurrence of at least $1 \mathrm{VLS} \geq 3$ during the first 70 DIM, and second, lameness was defined as the occurrence of at least $1 \mathrm{VLS} \geq 4$. The 2 lameness variables were tested in separate models.

\section{Statistical Analyses}

An increasing or decreasing trend in the occurrence of VLS $\geq 3$ by parity was analyzed by the Cochran-Armitage trend test using the FREQ procedure of SAS 9.1 (SAS Institute, Cary, NC). To facilitate analyses and results interpretation, the variable parity was categorized into 3 categories before they were used in all multivariable analyses. Parity group 1 was defined as first parity cows, parity group 2 was defined as second parity cows, and parity group 3 was defined as parity $\geq 3$. Season of calving was offered to the multivariable models. The year was divided into 4 seasons; December to February (winter), March to May (spring), June to August (summer), and September to November (fall). Twin parturition is a risk factor for other diseases; therefore, it was offered to the models.

Reproductive performance was measured as the calving-to-conception interval. Cows were censored for reproductive performance if pregnancy was not diagnosed before culling or death, if not pregnant in the first $305 \mathrm{~d}$ after calving, or the end of data collection. Cow survival was defined as days from calving to culling/death or censored. Cows were censored for survival if the cow survived beyond $305 \mathrm{~d}$ after calving, were dried off before $305 \mathrm{~d}$ after calving, or were still alive at the end of data collection.

The effect of lameness, defined as cow detected with at least 1 VLS $\geq 3$ or VLS $\geq 4$ in the first 70 DIM, on days from calving to conception and cow survival were analyzed by Cox's proportional hazard using the TPHREG (test proportional hazards regression) procedure of SAS. The time variables used in the models were days from calving to conception or censored and days from calving until culled/death or censored. The variables offered to the models were lameness, parity group, twin parturition, and season of calving. The variable farm was used in the model as a stratum variable to adjust for location. Backward variable elimination (Cantor, 1997) considering main effects and 2-way interactions between lameness cohorts and the other independent variables was performed. Variables were retained in the model when their main effect or their interaction with the variable lameness had a 2 -sided $P$-value $\leq 0.10$. 


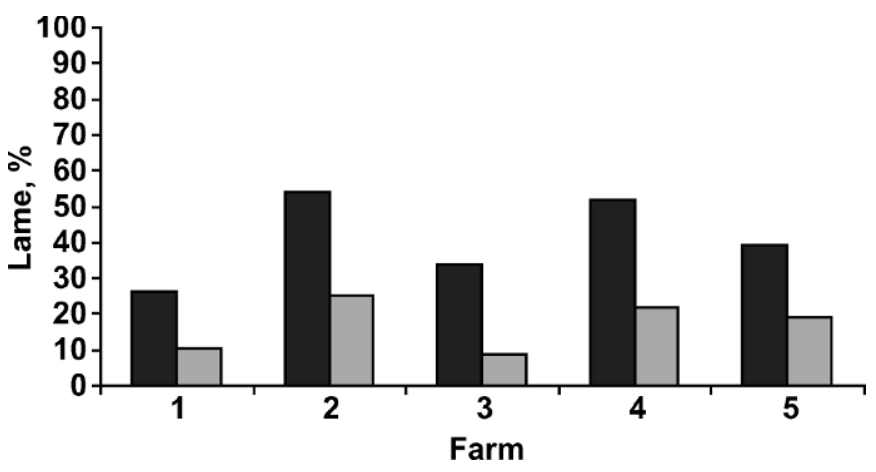

Figure 1. Proportion of cows detected with visual locomotion score (VLS) $\geq 3$ (black bars) and cows detected with VLS $\geq 4$ (gray bars) by farm, in the first 70 DIM.

Variables were considered statistically significant when a $P$-value $\leq 0.05$ was detected, and a tendency to significance was considered if the $P$-value was between 0.05 to 0.10 . The analysis outcome is presented as hazard ratio (Spruance et al., 2004).

\section{RESULTS AND DISCUSSION}

In total 1,799 cows were enrolled, of which 549 were first-parity cows, 538 were second, and 712 were third or greater. A total of 494, 48, 56, 982, and 219 of cows were enrolled for farms $1,2,3,4$, and 5, respectively. The farm-specific cow-level prevalence of lameness (VLS $\geq 3$ ), was $26.5,54.2,33.9,51.8$, and $39.3 \%$, respectively (Figure 1). The total occurrence of lameness (VLS $\geq 3$ ) across the study was $42.9 \%(\mathrm{n}=1,799)$. The prevalence of lameness decreased $(P<0.001)$ from the first VLS until the fifth VLS (VLS1 25.3\%, n = 1,799; VLS2 24.4\%, $\mathrm{n}=1,675$; VLS3 20.2\%, $\mathrm{n}=883$; VLS4 19.2\%, $\mathrm{n}=822$; VLS5 19.5, $\mathrm{n}=601$ ).

Espejo et al. (2006), analyzing a large data set in Minnesota, reported a prevalence of lameness (as detected by VLS) of $24.6 \%$ with a range of 3.3 to $57.3 \%$. Wells et al. (1993) reported a lameness prevalence of $16.7 \%$ during the winter and $13.7 \%$ during the summer. Herein the occurrence of lameness was defined twice as the occurrence of at least one VLS $>2$ and at least one VLS $>3$ assessed only in the first 70 DIM. Lameness prevalence may be higher in the first 4 mo lactation when compared with the remainder of the lactation (Rowlands et al., 1985). Whereas cows received 2.5 VLS during the first 70 DIM, we considered cows lame if at least one of the repeated scores was $\geq 3$. This might have increased our sensitivity, but could have caused an overestimation of the occurrence of lameness due to misclassification. Bicalho et al. (2007) reported that the sensitivity and specificity of VLS for detecting painful foot lesions were 67.2 and $84.6 \%$ respectively; moreover, claw disorders

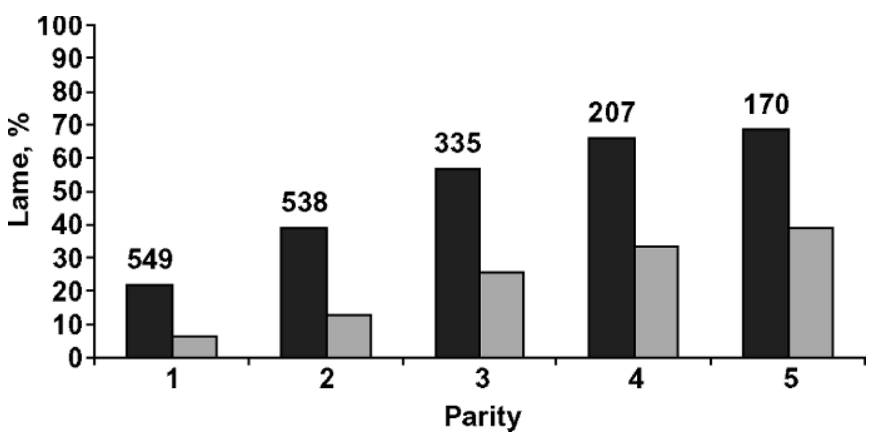

Figure 2. Proportion of cows detected with visual locomotion score (VLS) $\geq 3$ (black bars) and cows detected with VLS $\geq 4$ (gray bars) by parity, in the first 70 DIM. The numbers above the bars represent the total number of cows per parity. Cows with parity $\geq 5$ were grouped into category 5. A strong increase in the occurrence of lameness was detected as parity increased $(P<0.001)$.

account for approximately $90 \%$ of lameness in dairy cattle (Murray et al., 1996).

The prevalence of lameness increased significantly $(P$ $<0.001$ ) as parity number increased; for parity 1 , only $21.9 \%$ of the cows were classified as lame, whereas for parity $\geq 362.2 \%$ of the cows were classified as lame (Figure 2). A strong positive association of lameness prevalence with parity was reported (Wells et al., 1993; Espejo et al., 2006).

We observed an increase in days from calving-to-conception for lame cows $(P=0.019)$. In total of 1,762 cows were used for the Cox's regression analysis, of which $60 \%$ were detected pregnant by the end of data collection (Table 1). The only variables retained in the model were: lameness, parity group, season at calving, and farm, which was used as a strata variable. There were no significant interactions in the models. The hazard ratio of been detected pregnant was $0.85(\mathrm{SE}=0.07 ; P=0.019)$ for lame cows (VLS $\geq 3$ ) vs. nonlame cows; hence, lame cows were $15 \%$ less likely to be detected pregnant com-

Table 1. Cox's proportional hazards summary of the number of events (pregnancies) and number of censored cows by farm

\begin{tabular}{lrrcc}
\hline $\begin{array}{l}\text { Farm } \\
\text { number }^{1}\end{array}$ & $\mathrm{n}^{2}$ & Event $^{3}$ & Censored, $\mathrm{n}$ & Censored. \% \\
\hline 1 & 475 & 226 & 249 & 52.4 \\
2 & 46 & 30 & 16 & 34.8 \\
3 & 54 & 43 & 11 & 20.4 \\
4 & 971 & 593 & 378 & 38.9 \\
5 & 216 & 163 & 53 & 24.5 \\
Total & 1,762 & 1,055 & 707 & 40.1 \\
\hline
\end{tabular}

${ }^{1}$ Farms 1, 2, and 3 from Lewis County, NY; farms 4 and 5 from Cayuga County, NY.

${ }^{2} \mathrm{n}=$ total number of animals enrolled per farm.

${ }^{3}$ Event $=$ Number of events $($ culling/death $)$ per farm. 
Table 2. Cox's proportional hazards analysis outcome table for calving-to-conception ${ }^{1}$ interval to test the effect of visual locomotion score (VLS) in the first 70 DIM

\begin{tabular}{|c|c|c|c|c|}
\hline Variable & $\begin{array}{c}\text { Parameter } \\
\text { estimate }\end{array}$ & SE & $\begin{array}{c}\text { Hazard } \\
\text { ratio }\end{array}$ & $P$-valu \\
\hline \multicolumn{5}{|l|}{ Lameness defined as VLS $\geq 3$} \\
\hline VLS $\geq 3$ vs. VLS $\leq 2$ & -0.17 & 0.07 & 0.85 & 0.019 \\
\hline Parity 2 vs. parity 1 & -0.04 & 0.08 & 0.96 & 0.64 \\
\hline Parity $\geq 3$ vs. parity 1 & -0.18 & 0.08 & 0.83 & $0.02 s$ \\
\hline Calved in spring vs. winter & -0.86 & 0.26 & 0.42 & 0.001 \\
\hline Calved i & 0.69 & 0.15 & 1.99 & $<0.00$ \\
\hline Calved in fall vs. winter & 0.34 & 0.08 & 1.40 & $<0.00$ \\
\hline \multicolumn{5}{|l|}{ Lameness defined as VLS $\geq 4$} \\
\hline VLS $\geq 4$ vs. VLS $\leq 3$ & -0.27 & 0.09 & 0.76 & 0.00 \\
\hline Parit & -0 . & 0.08 & 6 & 0.58 \\
\hline Parity $\geq 3$ vs. parity 1 & -0.18 & 0.08 & 0.83 & 0.02 \\
\hline Calved in spring vs. winte & -0.88 & 0.26 & 0.41 & 0.00 \\
\hline Calved in summer vs. winter & 0.68 & 0.14 & 1.98 & $<0.001$ \\
\hline Calved in fall vs. winter & 0.34 & 0.08 & 1.41 & $<0.001$ \\
\hline
\end{tabular}

${ }^{1}$ Reproductive performance was measured as the calving-to-conception interval. Cows were censored for reproductive performance if pregnancy was not diagnosed before culling or death, if not pregnant to an insemination in the first $305 \mathrm{~d}$ after calving, or the end of data collection.

${ }^{2}$ The 4 seasons as defined in the northern hemisphere were used to classify season at calving.

pared with nonlame cows (Table 2). To illustrate the difference in days-to-conception between lame and nonlame cows a plot was done using Kaplan-Meier survival analysis; lame cows (VLS $\geq 3$ ) had median calving-toconception interval of $149 \mathrm{~d}$; compared with $119 \mathrm{~d}$ for the cows that maintained VLS $\leq 2(\mathrm{P}<0.001)$. Sprecher et al. (1997) using univariable analysis in a small data set (66 cows) reported that cows with VLS $>2$ had longer days to first service and days from calving to conception. Hernandez et al. (2005), using a modification of the Sprecher et al. (1997) scoring system, reported that nonlame cows became pregnant more quickly than lame cows.

To explore the biological gradient relationship of lameness and reproductive performance, lameness was redefined as the occurrence of at least one VLS $\geq 4$, the hazard of conceiving was further decreased for the cohort of lame cows. Cox's regression analysis was performed for the redefined lameness scoring, the hazard ratio of being detected pregnant was 0.76 ( $\mathrm{SE}=0.09 ; P=0.003$ ) for lame cows vs. nonlame cows; hence, lame cows (VLS $\geq 4$ ) were $24 \%$ less likely to be detected pregnant compared with nonlame cows (Table 2). The variables lameness, parity group, season at calving, and farm were retained in this model. The intensity of the losses caused by lameness is directly related to the intensity of lameness affecting the cows. Hernandez et al. (2005) reported that cows classified as mildly lame were at a $29 \%$ decreased hazard for pregnancy and severely lame cows at a 58\% decreased hazard of pregnancy when compared with nonlame controls. It is biologically plausible that the impact of lame-

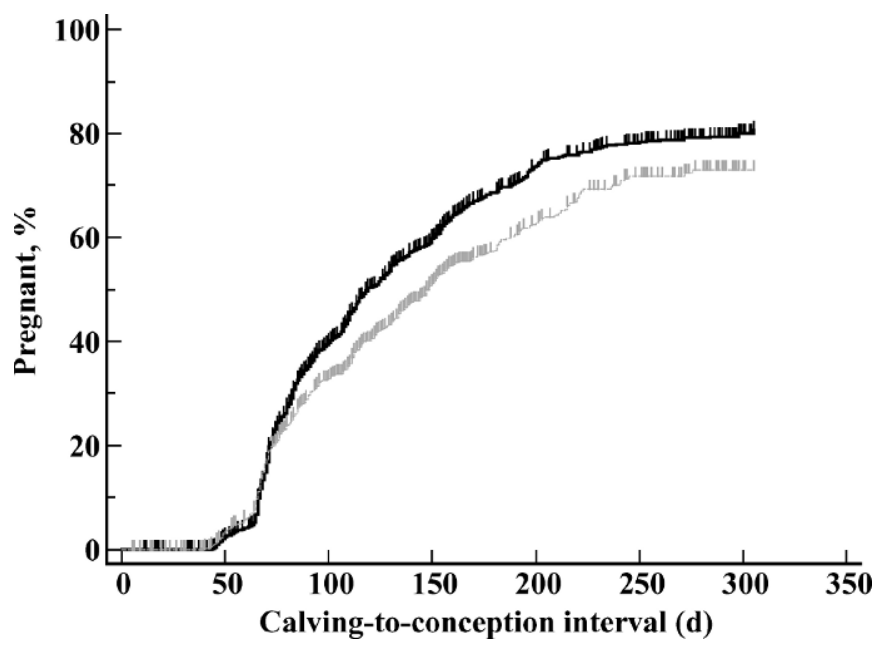

Figure 3. Kaplan-Meier survival analysis plot for calving-to-conception interval. Cows that were detected with visual locomotion score (VLS) $\geq 3$ (gray line) in the first 70 DIM had a median calvingto-conception interval of $149 \mathrm{~d}$ compared with $119 \mathrm{~d}$ for the cows that maintained VLS $\leq 2$ (black line; $P<0.001$ ). When lameness was redefined as VLS $\geq 4$ in the first 70 DIM, lame cows had a calvingto-conception interval of $158 \mathrm{~d}$ compared with $127 \mathrm{~d}$ for nonlame cows $(P<0.001)$. The straight marks in the curves represent time at censoring.

ness on reproduction is associated with the severity of lameness affecting the cows. A Kaplan-Meier survival analysis was performed to illustrate median calving-toconception interval for the 2 cohorts. Cows detected with a VLS $\geq 4$ in the first 70 DIM had a calving-to-conception interval of $158 \mathrm{~d}$ compared with $127 \mathrm{~d}$ for nonlame cows $(P<0.001$; Figure 3).

Our study was a prospective cohort observational study, and the cause and effect relationship could not be further explored. Previous studies have associated lameness, in the postpartum period, with higher incidence of ovarian cysts and delayed cyclicity (Melendez et al., 2003; Garbarino et al., 2004). Melendez et al. (2003) hypothesized that the higher incidence of ovarian cysts among lame cows may be caused by several factors including aggravated negative energy balance. Cows affected with lameness are exposed to considerable pain altering their behavior patterns, which may decrease DMI in the postpartum period as a consequence affecting ovarian activity (Lucy et al., 1992) and uterine health (Hammon et al., 2006). Garbarino et al. (2004) reported that lame cows had 3.5 times greater odds of delayed cyclicity than nonlame cows. Furthermore, it is possible that lame cows are less likely to express estrus and are less likely to be inseminated.

About $10 \%$ of all cows enrolled were culled or died during the data collection period (Table 3), but ranged from 5.5 to $32.6 \%$ for individual farms. The average annual culling rates in dairy farms ranged from 20 to $35 \%$ 
Table 3. Cox's proportional hazards summary of the number of events (culling/death) and number of censored cows by farm

\begin{tabular}{lrrcc}
\hline $\begin{array}{l}\text { Farm } \\
\text { number }\end{array}$ & $\mathrm{n}^{2}$ & Event $^{3}$ & Censored, $\mathrm{n}$ & Censored, \% \\
\hline 1 & 475 & 26 & 449 & 94.5 \\
2 & 46 & 15 & 31 & 67.4 \\
3 & 54 & 11 & 43 & 79.6 \\
4 & 971 & 107 & 864 & 89.0 \\
5 & 216 & 21 & 195 & 90.3 \\
Total & 1,762 & 180 & 1,582 & 89.8 \\
\hline
\end{tabular}

${ }^{1}$ Farms 1, 2, and 3 from Lewis County, NY; farms 4 and 5 from Cayuga County, NY.

${ }^{2} \mathrm{n}=$ Total number of animals enrolled per farm.

${ }^{3}$ Event $=$ Number of events (culling/death) per farm.

(Gröhn et al., 2003). In our study only $18 \%$ (of 1,762 ) of the cows were followed for more than 305 DIM and the median follow-up time for all cows enrolled was $249 \mathrm{~d}$; therefore, it was not possible to estimate average annual culling rate.

Lameness (VLS $\geq 3$ ) increased the hazard of culling/ death when compared with nonlame cows (VLS $\leq 2)$. The hazard ratio of culling/death was 1.45 (SE $=0.17 ; P=$ 0.03 ) for lame cows vs. nonlame cows; hence, cows with lameness were $45 \%$ less likely to be culled or die compared with nonlame cows (Table 4). Parity was significant; second-parity cows were 0.68 , and third-parity cows were 3.07 more likely to be culled or die compared with primiparous cows. Season at calving was significant and retained in the model; data clustering was controlled by adding farm in the model as a strata variable. Booth et al. (2004) analyzed the effect of lameness throughout

Table 4. Cox's proportional hazards analysis outcome table for survival $^{1}$ interval, to test the effect of visual locomotion score (VLS) in the first 70 DIM

\begin{tabular}{|c|c|c|c|c|}
\hline Variable & $\begin{array}{l}\text { Parameter } \\
\text { estimate }\end{array}$ & SE & $\begin{array}{c}\text { Hazard } \\
\text { ratio }\end{array}$ & $P$-valu \\
\hline \multicolumn{5}{|l|}{ Lameness defined as VLS $\geq 3$} \\
\hline VLS $\geq 3$ vs. VLS $\leq 2$ & 0.37 & 0.17 & 1.45 & 0.03 \\
\hline Parity 2 vs. parity 1 & 0.52 & 0.27 & 1.68 & 0.05 \\
\hline Parity $\geq 3$ vs. parity 1 & 1.40 & 0.24 & 4.07 & $<0.001$ \\
\hline Calved in spring vs. winter & 0.07 & 0.42 & 1.08 & 0.86 \\
\hline Calved & -2.05 & 0.77 & 0.13 & 0.007 \\
\hline Calved in fall vs. winter & -0.61 & 0.20 & 0.54 & 0.00 \\
\hline \multicolumn{5}{|l|}{ Lameness defined as VLS $\geq 4$} \\
\hline VLS $\geq 4$ vs. VLS $\leq 3$ & 0 & 0.17 & 1.74 & 0.00 \\
\hline Parit & 0.5 & 0.27 & 1.72 & 0.04 \\
\hline$\geq 3$ vs. parity 1 & 1.38 & 0.23 & 3.99 & $<0.00$ \\
\hline Calved in spring vs. winte & 0.13 & 0.42 & 1.14 & 0.76 \\
\hline Calved in summer vs. winter & -2.02 & 0.77 & 0.13 & 0.00 \\
\hline Calved in fall vs. winter & -0.62 & 0.20 & 0.54 & 0.00 \\
\hline
\end{tabular}

${ }^{1}$ Cow survival was measured as days from calving to culling or death. Cows were censored for survival if the cow survived beyond $305 \mathrm{~d}$ after calving, were dried off before $305 \mathrm{~d}$ after calving, or were still alive at the end of data collection.

${ }^{2}$ The 4 seasons as defined in the northern hemisphere were used to classify season at calving.

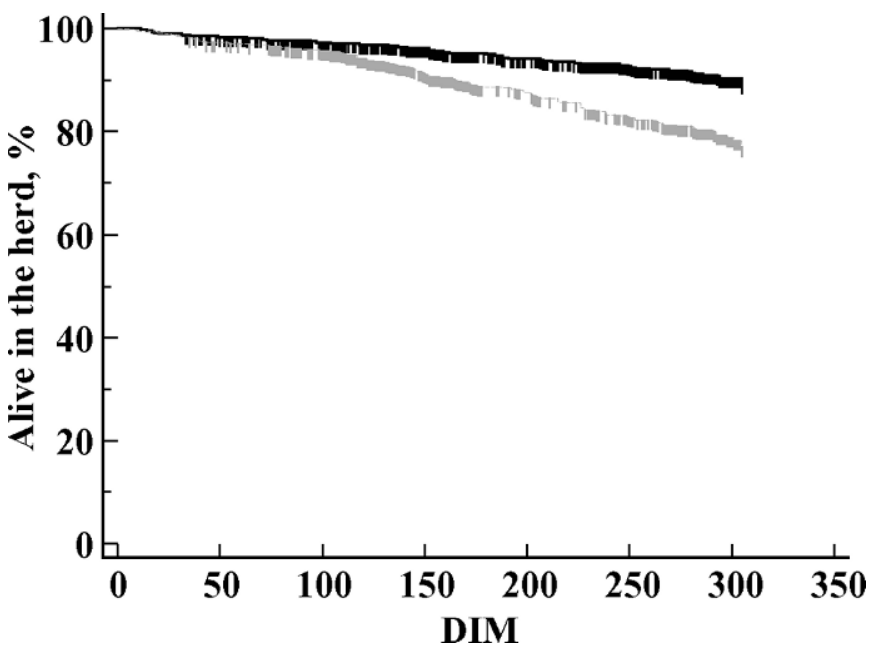

Figure 4. Kaplan-Meier survival analysis plot for survival interval (calving to culling/death interval). Cows that were detected with visual locomotion score (VLS) $\geq 3$ (gray line) in the first 70 DIM were at a higher hazard of culling/death when compared with cows that maintained VLS $\leq 2$ (black line) for the first 70 DIM (hazard ratio = $0.4495 \%$, confidence interval $=0.32-0.57 ; P<0.001$ ). Median survival days is not available because by the end of data collection both groups still had more than $50 \%$ of live cows. The straight marks in the curves represent time at censoring.

the lactation on cow survival and reported that cows classified as lame in the first 70 DIM had a $70 \%$ increased risk of being culled. In that that study, lameness was defined by presence of lesions at hoof trimming. RajalaSchultz and Gröhn (1999) reported that cows that were treated for foot-and-leg problems at the beginning of the lactation had a 6-times higher risk of being culled. In our study, when lameness was redefined as cows that received at least one VLS $\geq 4$, the hazard for culling/ death was 0.74 times (SE $=0.17 ; P=0.001$ ) higher for lame cows compared with nonlame cows. Our results agree with the results reported by Booth et al. (2004), but the increment in risk attributed to lameness that was reported by Rajala-Schultz and Gröhn (1999) was much higher than our findings. In that study lameness was defined as cows that received treatment by a veterinarian for a foot or leg problem. It is possible that the cohort of lame cows in that study included only severely affected cows. Furthermore, there might be important differences among the study populations; their study was performed using Ayrshire cows in Finland, whereas our study population was Holstein cows in upstate New York.

The increased culling/death rate in the cohort of lame cows can be explained by the direct debilitating effects on lameness; this effect would most likely cause a rapid disposal of cows after lameness, in our study within the first 70 DIM. Yet, the Kaplan-Meier survival analysis (Figure 4) showed that there was little difference be- 
tween the 2 cohorts up to 130 DIM. The increment in culling rate attributed to lameness is due to decreased milk production (Warnick et al., 2001) and increased days from calving to conception (Hernandez et al., 2001).

Lameness can occur during any stage of lactation, and the effect of lameness on reproduction and survival might depend on the time of its occurrence. Therefore, lameness may be a time-dependent covariate. The objective of our research was to determine the effect of lameness, when detected in the first 70 DIM, on days to conception and survival. With this restriction, the detected lameness would have been present before most of the first attempts to breed the cows. Information regarding the occurrence of other diseases was not collected for this study, the calving information (twin = yesno and season of calving) was available and was offered to the models; however, they were not significant. Booth et al. (2004) analyzed a large data set from New York and concluded that the effect of lameness on cow survival was not confounded by other diseases (clinical ketosis, left displaced abomasum, mastitis, milk fever, and retained placenta). Furthermore, Hernandez et al. (2005) reported that the prevalence of common postpartum diseases was well balanced between lame cows and nonlame cows, with the exception of clinical ketosis. Hence, the authors would like to acknowledge that optimally the most prevalent postpartum diseases should have been included in the models; however, it is unlikely that the effects attributed to lameness are confounded by these diseases.

\section{CONCLUSIONS}

A significant increase in days from calving to conception was observed for cows detected as lame when compared with those considered nonlame during the first 70 DIM. When lameness was defined as cows detected at least once with VLS $\geq 3$, the hazard ratio of been detected pregnant was 0.85 (VLS $\geq 3$ ) or 0.76 (VLS $\geq 4$ ) vs. nonlame cows. Lameness was associated with increased hazard of culling/death; the hazard ratio of culling/death was 1.45 (VLS $\geq 3$ ) or 1.74 (VLS $\geq 4$ ) for lame cows vs. nonlame cows.

\section{ACKNOWLEDGMENTS}

We are grateful to all dairy farmers who participated in the study for allowing the research project to be conducted in their farms.

\section{REFERENCES}

Bicalho, R. C., S. H. Cheong, G. Cramer, and C. L. Guard. 2007. Association between visual locomotion score and an automated locomotion score in lactating Holstein cows. J. Dairy Sci. 90:3294-3300.

Booth, C. J., L. D. Warnick, Y. T. Gröhn, D. O. Maizon, C. L. Guard, and D. Janssen. 2004. Effect of lameness on culling in dairy cows. J. Dairy Sci. 87:4115-4122.

Cantor, A. B. 1997. Pages 112-113 in Extending $\mathrm{SAS}^{\circledR}$ Survival Analysis Techniques for Medical Research. SAS Institute Inc., Cary, NC.

Espejo, L. A., M. I. Endres, and J. A. Salfer. 2006. Prevalence of lameness in high-producing Holstein cows housed in freestall barns in Minnesota. J. Dairy Sci. 89:3052-3058.

Esslemont, R. J., and M. A. Kossaibati. 1997. Culling in 50 dairy herds in England. Vet. Rec. 139:486-490.

Garbarino, E. J., J. A. Hernandez, J. K. Shearer, C. A. Risco, and W. W. Thatcher. 2004. Effect of lameness on ovarian activity in postpartum Holstein cows. J. Dairy Sci. 87:4123-4131.

Green, L. E., V. J. Hedges, Y. H. Schukken, R. W. Blowey, and A. J. Packington. 2002. The impact of clinical lameness on the milk yield of dairy cows. J. Dairy Sci. 85:2250-2256.

Gröhn, Y. T., P. J. Rajala-Schultz, H. G. Allore, M. A. DeLorenzo, J. A. Hertl, and D. T. Galligan. 2003. Optimizing replacement of dairy cows: Modeling the effects of diseases. Prev. Vet. Med. 61:27-43.

Hammon, D. S., I. M. Evjen, T. R. Dhiman, J. P. Goff, and J. L. Walters. 2006. Neutrofill function and energy status in Holstein cows with uterine health disorders. Vet. Immunol. Immunopathol. 113:2129.

Hernandez, J. A., E. J. Garbarino, J. K. Shearer, C. A. Risco, and W. T. Thatcher. 2005. Comparison of calving-to-conception interval in dairy cows with different degrees of lameness during the prebreeding postpartum period. J. Am. Vet. Med. Assoc. 227:12841291.

Hernandez, J., J. K. Shearer, and D. W. Webb. 2001. Effect of lameness on the calving-to-conception interval in dairy cows. J. Am. Vet. Med. Assoc. 218:1611-1614.

Lucy, M. C., C. R. Staples, W. W. Thatcher, P. S. Erickson, R. M. Cleale, and J. L. Firkins. 1992. Influence of diet composition, dry matter intake, milk production, and energy balance on time of postpartum ovulation and fertility in dairy cows. Anim. Prod. $54: 323-331$

Melendez, P., J. Bartolome, L. F. Archbald, and A. Donovan. 2003. The association between lameness, ovarian cysts and fertility in lactating dairy cows. Theriogenology 59:927-937.

Murray, R. D., D. Y. Downham, M. J. Clarkson, W. B. Faull, J. W. Hughes, F. J. Manson, J. B. Merritt, W. B. Russell, J. E. Sutherst, and W. R. Ward. 1996. Epidemiology of lameness in dairy cattle: Description and analysis of digit lesions. Vet. Rec. 138:586-591.

NRC. 2001. Nutrient Requirements of Dairy Cattle. 7th rev. ed. Natl. Acad. Sci., Washington, DC

Rajala-Schultz, P. J., and Y. T. Gröhn. 1999. Culling of dairy cows Part I. Effects of diseases on culling in Finnish Ayrshire cows. Prev. Vet. Med. 41:195-208.

Rowlands, G. J., A. M. Russell, and L. A. Wiliams. 1985. Effects of stage of lactation, month, age, origin, and heart girth on lameness in dairy cattle. Vet. Rec. 117:576-580.

Sprecher, D. J., D. E. Hosteler, and J. B. Kaneene. 1997. A lameness scoring system that uses posture and gait to predict dairy cattle reproductive performance. Theriogenology 47:1179-1187.

Spruance, S. L., J. E. Reid, M. Grace, and M. Samore. 2004. Hazard ratio in clinical trials. Antimicrob. Agents Chemother. 48:27872792.

Warnick, L. D., D. Janssen, C. L. Guard, and Y. T. Gröhn. 2001. The effect of lameness on milk production in dairy cows. J. Dairy Sci. 84:1988-1997.

Wells, S. J., A. M. Trent, W. E. Marsh, and R. A. Robinson. 1993. Prevalence and severity of lameness in lactating dairy cows in a sample of Minnesota and Wisconsin herds. J. Am. Vet. Med. Assoc. 202:78-82.

Whay, H. R., D. C. Main, L. E. Green, and A. J. Webster. 2003. Assessment of the welfare of dairy cattle using animal-based measurements: Direct observation and investigation of farm records. Vet. Rec. 153:197-202. 